A. K. MISHRA, G. PARVARI, S. K. SANTRA, A. BAZYLEVICH, O. DORFMAN, J. RAHAMIM, Y. EICHEN*, A. M. SZPILMAN* (TECHNION - ISRAEL INSTITUTE OF TECHNOLOGY, HAIFA AND ARIEL UNIVERSITY, ISRAEL)

Solar and Visible Light Assisted Peptide Coupling

Angew. Chem. Int. Ed. 2021, 60, 12406-12412, DOI: 10.1002/anie.202011510.

\section{Solar Radiation-Assisted Peptide-Bond Formation}

(Sun)<smiles>CCC(NC(=O)C(=O)O)C(=O)O</smiles><smiles>O=C(O)C([18OH])NCO</smiles>

(1.0 equiv)

(2.0 equiv)

\section{Category}

Peptide Chemistry

\section{Key words}

peptide bond formation

photocatalysis

solar radiation

bromotrichloro-

methane

radical reaction<smiles>COC(=O)[C@H](Cc1ccccc1)NC(=O)CNC(F)(F)F</smiles>

$50 \mathrm{~min}, 92 \%$ yield<smiles>CCC(C)C(NC(F)F)C(=O)N[C@@H](Cc1ccccc1)C(=O)OC</smiles>

$60 \mathrm{~min}, 83 \%$ yield<smiles>CCOC(=O)CNC(=O)C(C[18O])NC(F)F</smiles>

$60 \mathrm{~min}, 77 \%$ yield<smiles>CCOC(=O)CNC(=O)C(Cc1ccccc1)NC(=O)OCc1ccccc1</smiles>

45 min, $91 \%$ yield<smiles>CCOC(=O)CNC(=O)C(Cc1ccccc1)NC(F)F</smiles>

$45 \mathrm{~min}, 82 \%$ yield<smiles>CCOC(=O)CNC(=O)C(NC(C)(C)C)[C@H](C)OC(C)(C)C</smiles>

$60 \mathrm{~min}, 85 \%$ yield<smiles>CCOC(=O)CNC(=O)C(Cc1cn(C)cn1)NCF</smiles>

$60 \mathrm{~min}, 71 \%$ yield<smiles>CCCC[C@H](NC(=O)C(Cc1ccccc1)NC(=O)c1ccccc1)C(=O)OC</smiles>

$60 \mathrm{~min}, 88 \%$ yield<smiles>CCOC(=O)CNC(=O)C(NC(F)F)C(C)CC</smiles>

$60 \mathrm{~min}, 79 \%$ yield<smiles>CCOC(=O)CNC(=O)C(CC(=O)OC(C)(C)C)NC(=O)OCC</smiles>

$60 \mathrm{~min}, 89 \%$ yield<smiles>COC(=O)[C@H](Cc1ccccc1)NC(=O)CNC(=O)OC(C)(C)C</smiles>

$60 \mathrm{~min}, 87 \%$ yield<smiles>COC(=O)[C@H](CC(C)C)NC(=O)C(COCc1ccccc1)NC(=O)OC(C)(C)C</smiles>

$60 \mathrm{~min}, 91 \%$ yield
Significance: Amide bond formation is extremely important in peptide chemistry. The authors have developed a sunlight-assisted method for generating active coupling reagent in situ from readily available DMAP and bromotrichloromethane to form peptide bonds.
Comment: Various dipeptides can be synthesized by using DMAP and bromotrichloromethane to generate the active coupling reagent. The reactions proceed rapidly, and the yields of the desired peptides are good to excellent. 